\title{
The Baby as a Virtual Object: Agency and Stability in a Neonatal Care Unit
}

\section{El bebé como objeto virtual: agencia y estabilidad en una unidad de cuidado}

\author{
David Middleton \& Steven Brown \\ Department of Human Sciences, \\ Loughborough University, \\ Loughborough, \\ Leicestershire, UK \\ LE11 3TU
}

\section{D.J.Middleton@lboro.ac.uk s.d.brown@lboro.ac.uk}

\begin{abstract}
Neonatal care work is a complex social practice. It maybe understood as a network in which doctors, babies, parents, technology and medicalcare are aligned together in relationships dominated by issues of accountability. The nature of neonatal care means that the boundaries of what counts as the unit are always shifting. The regular appearance of new members, new patients and new technologies mean that much effort must be expended to hold the unit together as a functional entity. Thus stability in the unit's practice, rather than change, is something to be explained. Equally, ambiguity and uncertainty rather than clarity and procedure are important features of neonatal care.
\end{abstract}

We examine how the baby (i.e. the neonate receiving care) acts the 'object' around which the unit is continuously ordered. The identity of the baby - what it is, what attributes are considered important, what effects it generates - is changeable. Staff constantly 'scale up' and 'scale down' what the baby is from a child to a biological system in accord with contextual demands (i.e. the baby's likely trajectory of care). The agency of the baby is often a resource that is worked up and generated by the network itself during this process of scaling. In this sense the baby is a 'virtual object' which cycles through various identities and relationships. We outline how this cycling appears to operate and the way in which it serves to hold together neonatal care work.

Keywords: techonology, neonatal care, virtuality, subjectivity, agency, social change.

\section{Resumen}

La compleja práctica social del cuidado neonatal puede entenderse como una red en la que los doctores, los bebés, los padres, la tecnología y el cuidado médico se alinean en relaciones dominadas por la necesidad de rendir cuentas de la acción. La naturaleza del cuidado neonatal obliga a desplazar continuamente las fronteras de los objetos que lo conforman. La constante aparición de nuevos miembros, pacientes y tecnologías requiere dedicar grandes esfuerzos a la conservación de la unidad funcional de la institución. En consecuencia, es la estabilidad de esta práctica, y no su modificación, la incógnita a explicar. Asimismo, son la ambigüedad y la incertidumbre (y no la claridad y el orden de los procedimientos) sus aspectos más importantes. "En este artículo se examina cómo el bebé (el neonato que recibe los

cuidados) deviene el "objeto" en torno al cual se organiza la unidad. La identidad del bebé (qué es, cuáles de sus atributos son relevantes, qué efectos genera) es proteica: el personal pasa de verlo como "un sistema biológico" a verlo como "un niño" en función de las demandas contextuales (como la trayectoria de cuidado del bebé). La 
agencia del bebé es frecuentemente un recurso que la red misma genera y constituye a lo largo de este proceso. En este sentido, el bebé es un "objeto virtual" que circula a través de varias identidades y relaciones. Se examina el modo en que esta circulación opera, y cómo permite afianzar la práctica del cuidado neonatal".

Palabras clave: tecnología, cuidado neonatal, virtualidad, subjetividad, agencia, cambio social

\section{Introduction}

Much effort has been expended in recent times by social scientists — psychologists included — in coming to terms with the ubiquitous presence of technology in our lives. Of particular significance is the use of information communication technologies (ICT) - from the Internet and email to mobile phones and personal organisers - and the ways in which they act as common mediators of social interaction. They organise our schedules, our contacts, our forms of communication. Which is to say that ICT's play a crucial role in producing the interactional orders of modern Western societies.

But there is a caveat to this observation. Despite their prominence and obvious potential for restructuring social relations, the direction of influence is not one way. ICT's may remediate the ways were late and communicate to one another, but the social relations also reconfigure and shape the nature of the technology itself. Email, for example, makes possible sophisticated forms of communication, but what email is - that is, the way it is treated, defined, used and exploited depends substantially upon the context and community in which it is deployed. Hence email use in large corporate organisations can be substantially and qualitatively different from email use in, say, universities (Brown \& Lightfoot, 2002).

So rather than simply address technology as a thing-in-itself to be studied, we can recognise that technology is one aspect of how modern social ordering is achieved, whether this be in the form of an organisation, a 'community of practice', or a family. Latour (1992) has analysed in close detail how technologies may crystallise certain forms of social relations and possibilities for action. An engine immobiliser on a car, for example, when connected to a seat belt catch may effectively enforce a prescription to always wear a seat belt when driving. A moral imperative is then given a material form. Similarly, Hendriks (1997) has shown how the relations between carers and autistic young adults may become embedded in simple mechanical devices like egg timers. Here the technology - the egg timer - materialises the carer's demands that the autistic adult spend only specified amounts of time on certain tasks. Finally, the design of email systems which include copying and blind copying facilities may lend shape to the strategies managers and employees use to display their accountability to one another and the way in which 'memory' becomes an issue in an organisation (Brown, Middleton, Lightfoot, 2001). Again, although the technology is the ostensible object to be investigated, what really matters are the kinds of social ordering it performs through its contextual use.

This line of theorising and research - which owes much to the work of Bruno Latour and Actornetwork theory - is currently underdeveloped in social psychology (but see Bayer \& Shotter 1997; Gordo-Lopez \& Parker 1999; Michael 2000). This paper contributes to recent work attempting to develop studies of technology and social ordering (Domènech and Tirado 2001; Woodrow 2001; Rodríguez, López, and Vitores 2001). These studies recognise that the relationship between 
technology and sociality is indeterminate in several ways. At a mundane level, we simply do not know in advance what precisely a given piece of technology may do when put in place in a particular social setting. Nor do we know what shape social relations may ultimately take as a result of the remediation performed by the artefact. The more subtle point is that if we do not know what sort of thing the artefact will turn out to be, then equally we cannot predict what kinds of relations, what ways of being together, will result when this thing comes in-between the people in the setting.

What we are looking for is a way of talking about this indeterminacy. Or rather of recognising that at any extant moment in the relationship between people and things, there exist numerous possibilities for alternate arrangements. This potential is in every sense 'real'. For example, Woodrow (2001) describes how a digital camera is for some user groups a discrete artefact that enables immediate processing of images. Yet amateur photographers treat this same artefact as an inferior input device for image manipulation software, which they see as the core element of digital photography. These are two possible configurations of the same artefact, two ways of realising what this thing is. Both are concrete realities that come about through the adoption of the artefact in a specific setting.

We propose the term virtual as an analytic device for understanding the relationship between technology and social action. Virtuality is now commonly used as a synonym for the Internet and other technologies which affect different place / different time or different place / same time communication. We suggest that this usage is somewhat unhelpful, since it ignores a rich philosophical seam of ideas around the notion of the virtual. The work of Gilles Deleuze (1997) and Michel Serres $(1995 ; 1997)$ in recent times, for example. And the earlier thought of Henri Bergson and Alfred North Whitehead. This tradition of work opposes the virtual to the actual, in distinction to the similar sounding opposition of possibility and reality (which used to refer to quantitative probabilities). Crudely put, the virtual is the potential forms of identity and attributes that a thing might come to be accorded. It is potential qualities and modes of action, if you like. The actual is the given identity and attributes that are identified when a thing is grasped and recognised as such and such an entity. What it actual appears to be and do when encountered in a given circumstance. It follows that the actual is constantly revisable - different methods of ordering the world might render the thing in another way entirely. So in a sense the actual, what we make of something here and now, is a kind of solution, a way of achieving a settlement, albeit of a provisional nature. This solution is premised on the virtual as a problem.

Take, for example, Bruno Latour's (1988) wellknown example of Pasteur's discovery of the role of microbes in lactic fermentation. Latour argues that Pasteur's triumph is to have shaped the phenomenon is such a way that the identity microbe might be given to yeast. This, Latour implies, is not determined by the nature of fermentation itself: through a series of trials Pasteur makes actual one possible arrangement of identities and relationships. Other arrangements were possible - although this is difficult for us, who live in a 'Pasteurised' world, to conceive. Pasteur's work orders materials and relation, and in so doing assigns identities. This is the essence of net-working, as Latour and the actor-network theory present it.

So the making actual of a set of identities and relationships is a feat of ordering. An organisational form is given which seeks to guarantee the repeated enactment of one set of potential connections and programmes of action. This is what Latour describes as he shows Pasteur engineering successive trials of force which will stabilise the relationship between microbes and people. He makes the relationship between microbes and people part of the infrastructure of mid-nineteenth century society, and in so doing, of course, makes himself indispensable to this newly ordered organisational form. 
What the term virtuality makes visible is the processual aspects of an organisation - how it becomes what it is, and the movements and relationships which are opened up or foreclosed upon. For example, a hospital unit may be considered as a virtual entity in so far as it exists as a distributed and constantly changing array of personnel, patients, technologies, practices and settings. This array forms a kind of network, only part of which is likely to be visible at any one time (Middleton, Brown and Curnock 2000). Equally, an event such as an environmental disaster may be understood as virtual in that it involves a loosely coupled collection of persons, animals, machines and social policies — not forgetting 'the environment' itself — which interact together in complex and unpredictable ways over relatively short spaces of time (López, Rodríguez and Vitores 2001).

\section{Virtuality}

The virtual is then a way of analysing organisational forms and events which is sensitive to the role of technology as a means of securing social order. Common issues to be addressed might include: how does this piece of technology become oriented to, defined and used by participants over time? How are social relations remediated and reworked by a given material object? What are the apparent boundaries of the networked array of actors and materials, and how do they appear to evolve? What possibilities for action are structured by the current networked relationships and what possibilities are foreclosed upon? In particular, drawing on the work of Levy (1998) and Deleuze (1997) we offer an illustration of how virtuality may be used as the basis for a sustained analysis of a complex organisation.

We describe how the child plays a central, yet ambiguous role, in holding together neonatal intensive care as a practice. Through analysing the way in which the identity, agency and powers of the child are actualised according to contextual demands, we show how the virtual character of an organisational form offers a critical and challenging object for study. In so doing we identify three senses in which the notion of the virtual contributes to a performative social psychology of organisations. All three senses of the virtual reconfigure the way we understand the organisational dynamic of contingent work practices. First what one does today is a 'solution' to a constantly changing array of 'problems'. This is not some playing out of the relationships between the realities and possibilities of practice. The distinction between the real and the possible does not allow for emergent improvisation and creativity in the stock and flux of organisational order and disorder. Rather the concern is with the interdependencies of the virtual and actual. Such interdependencies provide the basis for serendipity and improvisation in the recycling of potential connections in the way order is actualised from virtual potentiality of arrangements of persons, materials and technology. Secondly, the potential of things always exceeds their current actualisation. Finally things are never singular, that is, they are always potentially multiple, but get stabilised as different discrete things as part of ongoing projects.

\section{Setting-Neonatal Intensive Care}

This paper draws on material recorded in a multi-disciplinary health care setting concerning the conduct and practice of intensive care with families of new-born children. Neonatal care work is a complex social practice. It may be understood as a network in which doctors, babies, parents, technology and medical care are aligned together in relationships dominated by issues of 
accountability. At the heart of such practice is an ambiguous entity - the premature neonate who is neither fully 'social' nor completely 'natural' (since they owe their existence to technology and medical expertise). The nature of neonatal care means that the boundaries of what counts as the unit are always shifting. The regular appearance of new members, new patients and new technologies mean that much effort must be expended to hold the unit together as a functional entity. Thus stability in the unit's practice, rather than change, is something to be explained. Equally, ambiguity and uncertainty rather than clarity and procedure are important features of neonatal care. In what follows, we use the notion of virtuality to understand the production of stability in the midst of constant ambiguity.

\section{Producing Organisational Stability}

How is stability produced in such circumstances? Participants in neonatal intensive care continually orient to the production of stabilities in practice. They spend much effort trying to ensure that an organisational form holds steady around the neonate. In achieving this, participants display awareness of the contingency of work upon a shifting array of knowledges, materials, personnel and circumstances. They act in the face of radical uncertainty. The following example of talk recorded in a routine meeting specifically convened to address the uncertainties of practice:

\section{Sequence 1}

SR: [...] now the vitamin $\mathrm{K}$ comes up every week I've thought about this and I think the system that might work but in fact I think we need Dr Smith here would be that where a baby is born in the labour suite we have a slip which has got a sticky back and one of them other's stickers goes on that slip and that's either stamped or it's pre-printed with the vitamin $\mathrm{K}$ prescription and most slips could go onto a clip on each post natal ward so that when you come to the post natal wards you're signing this slip you wouldn't be looking around for the notes and then the ward clerk put those signed slips in the notes that would mean that babies didn't get missed it would mean you didn't have to look for the notes and it wouldn't involve any extra work except for the ward receptionist who would already be putting results into notes it would still mean that there was a problem in as much as you're only visiting each post natal ward once a day any advances on that system? anybody got any problems with that system?

Sho1: Why can't the obstetricians — I mean?

SR: $\quad$ Because we've already had that debate and they won't [

Sho2:

[but Miss Jones's requested

them to apparently[

SR: well they won't I mean that's already been explored I think by Dr Smith in depth and er they're prescriptions for babies and we're paediatricians that's the argument

Sho1: But they're doing more to see every mother routinely without bias

SR: Well if you want to pursue that argument I think it'll be much more tortuous and erm probably eventually unsuccessful because the babies because we're paediatricians

$[\ldots]$ 
SR: The reason for having a slip is to disassociate it from the notes which you've been telling me are difficult to get hold of that you have problems getting hold of the mother's notes so if the slip goes in the notes it might as well be in the notes the stamp might as well be in - there's no advance on the present system

This interaction deals with a long standing problem. It is national practice to routinely provide vitamin $\mathrm{K}$ injections to new born babies. For babies delivered without complications, this is usually straight forward. But babies in the neonatal care unit are subject to such a wide range of procedures that the vitamin $\mathrm{K}$ injections may fall by the way side. What the SR proposes is a formal solution to the problem, involving a system of slips. The SHOes question the likely effectiveness of the system, providing an opportunity for the SHO to 'do history', in this case how the problem has been knocked back and forth between groups of medical practitioners.

What we see here is members making visible in their talk an awareness that current knowledge and practice is only provisional. What one does today is a 'solution' to a constantly changing array of 'problems'. This problem is how to enmesh babies in a stable way into a constantly changing set of local circumstances. In addressing the problem, the members make actual all sorts of relationships between different practitioner groups, different wards within the hospital and different sorts of files and records. The question is how to understand the organisation of work in these conditions? What sort of analysis provides an adequate account for how stabilities inpractice - like the proposed vitamin $\mathrm{K}$ slips - are accomplished?

\section{Social Networks}

This is a well established unit with a long track record in the delivery of neonatal care. This is no training simulation, yet we see that roles, norms, rules and procedures are all up for grabs. Granted, the junior doctors are learning on the job. At this point they are three months into a six month rotation in training on the Unit but what we have seen in sequence 1 is more than an explanation of custom and practice to new and inexperienced team members. At issue is the invention of a routine that will stabilise in a reliable manner the ordered administration of a drug so that all babies receive it. Who should do what in and what circumstances is not determined in any direct way by professional role. The norms of behaviour are not reliably tied to such roles. Neither roles nor any such associated norms or rules of order provide for certainty in dealing with such issues. Roles, norms, rules and procedures cannot be taken for granted. The talk provides a way of establishing the nature of team practice. So right away we must reject an analysis that would treat an organisational structure of norms, rules and procedures as pure givens (such as social network analysis, cf. Burt 1982; Wasserman and Galaskiewicz 1994).

Networks constituted on the basis of supposedly socially structured relations rely upon continuities of identities and memberships for their stability (Strathern 1995). Previous work on collectivity in team work was concerned with how such stabilities of roles, norms and procedures are accomplished in team talk (Middleton 1996a; 1997a; 1997b; 1998; 2002). That work focused on how identity and collectivity are made topics of concern in establishing and maintaining coordinations in team practice. Team work is therefore studied as a performative accomplishment realised in and through communicative action. Overall, analysis focused on the ways continuities of experience and expertise are maintained and repaired in the context of changing demands, cases and staff in a variety of 
paediatric care settings (e.g., diagnosis of developmental delay, Middleton 1996a) and paediatric renal care (Middleton 1996b).

\section{Performative Networks}

A key focus of such communicative analysis is the way participants turn around on what it is to work in a co-ordinated and mutually accountable manner as multi-professional and disciplinary teams. How do groups of people work up what it is to co-ordinate and reco-ordinate multi-disciplinary teamworking? Of particular analytic concern was the way they establish interdependencies in the individual and social relevance of work place experience and expertise. In other words, how what it is to be a member becomes a topic of discursive concern for participants working as a team especially at times when the flow of work is subject to reco-ordination.

One way into such "recenterings" is to examine the way uncertainties of practice are made individually and collectively relevant in the semiotic regulation of work (Raeithel 1994; 1996, Middleton and Curnock [in press]). Furthermore one way to investigate in detail the semiotic use of uncertainty is to examine the social organisation of remembering and forgetting in team work (Middleton 1997b). That is the ways in which continuities and discontinuities of past, present and future practice are made visible in the communicative dynamic reordering of just what need or need not be attended to. Such analysis was concerned to identify improvised emergent social ordering in team talk. In so doing it drew on a long tradition of ethnomethodolically informed work place studies analysising interaction in institutional settings (eg., Drew and Heritage 1992; Boden and Zimmerman 1991) and discursive psychology (Billig 1987; Potter and Wetherell 1987; Potter and Edwards 1992).

\section{Actor-Networks}

Whilst such work provides for an understanding of the ways in which we establish in communicative action forms of social order, there is a sense in which it still misses an essential feature of the ways in which complex work settings are subject to emergent orderings. There is something more than talk-ininteraction that holds us together. If we look to the deconstruction of the 'social' in recent sociology we find another perspective on a performative analysis of collectivity in team working. Actor-network theory, as developed in the work of Bruno Latour and his colleagues Michel Callon, Madeliene Akrich, John Law and others (Law 1992a), offers a powerful alternative to social network analysis. Strathern (1995) pithily captures the difference when she notes that "[actor] network imagery offers a vision of social analysis that will treat social and technological items alike; any entity or material can qualify for attention".

Actor-networks are analysed as emergent alliances formed between human and non-human entities (see Callon 1986 for a classic demonstration). The concept of actor-networks made up of a tracery of heterogeneous elements (human and non-human, culture and nature, technology and society) challenges reductive approaches to social and psychological analysis. Social structure is not treated as some bedrock of roles, norms, rules and procedures that determine or effect the order and diversity of human behaviour, but as an emergent effect of ongoing processes of ordering:

"[S]ociety, organisations, agents and machines are all effects generated in patterned networks of diverse (not simply human) materials" (Law 1992b). 
Such analysis challenges the idea that the 'social' holds us together. It proposes instead that by virtue of the mediation of non-humans and materials sociality is formed:

"If human beings form a social network it is not because they interact with other human beings, it is because they interact with human beings and endless other materials too' (Law 1992b).

The notion of actor-network provides a way of tracing how human and non human entities are held together in social interaction. Such networks are hybrids whose critical force, as Strathern (1995) argues, challenges the notion of pure form which separates out for analytical convenience "technology and society, culture from nature and human from non human" (p. 520). One of the key analytic moves in actor-network analysis is to examine translations and inscriptions in the flow and topology of heterogeneous networks. In so doing we have illustrated the first sense of virtuality. How what one does today is a 'solution' to a constantly changing array of 'problems'.

\section{Translations}

\section{Inscriptions and Punctualisation/Blackboxing}

Let's return to Sequence 1. Here we see invoked as a direct concern the question of which professional agency, paediatricians or obstetricians, will be responsible for administering vitamin $\mathrm{K}$ to babies born on the labour unit. We see an interesting translation of agency and accountability into a suggested inscription of the sticky back slip. The slip is a potential instantiation of auditable accountability and agency of team practice. It brings together two separate forms of established inscriptions in the setting. The identification stickers that are already a feature of routinised record keeping for each mother and a modification of the way drug prescriptions are used.

How does the creation of 'the sticky back slip', the mother's identity sticker and the blank prescription, generate the potential organisational effect? Its potentiality resides in the way it translates human agency and accountability. The fallibility of a process that requires people to search and check notes is translated and inscribed into a potential artefact - a blank 'stickyback slip' - that has identity and prescription already inscribed and that just requires the signature of the paediatrician. The flow of work would now move through the use of this artefact which stabilises the fallibility of human agency by translating the process into an inscription that provides for guaranteed accountability.

Such inscriptions punctualise ('blackbox') or conceal from view the ordering of work (Law 1992b). Indeed the power of such punctualisation/blackboxing is used as a basis for arguing that potential system as an advance on the current ordering of practice in the unit vis à vis the prescription of vitamin $\mathrm{K}$. It is precisely because of the potential of such procedure that it can be taken for granted that the conditions for reliably delivering the drug obtain. It offers a way of drawing established inscriptions and flows of work without having to deal with the endless complexities such as searching for notes in the middle of the night. The baby's identity for the purposes of administrating vitamin $\mathrm{K}$ is actualised in the translations of practice in the inscriptions on the 'sticky back slip'. This inscription would actualise the identity of the baby (as someone who stands in need of receiving vitamin $\mathrm{K}$ ) in the network of care in ways that are argued as coping with the radical contingencies and uncertainties of practice. 
Producing stabilities in practice is about producing stabilities in flows and circulation of the baby as an object of care. But as we see here, whether or not such a system stems the flow in ways that manage the contingencies and uncertainties of practice remains problematic. The point we want to stress is that the negotiations about mundane practices like providing vitamin $\mathrm{K}$ settle the identity of the baby in one particular way. Babies are either 'caught' by the process or not. That is the way the 'sticky blank slip' renders the baby. In terms of the flow of care, the baby plus sticky blank slip constitutes a subtly different kind of entity to the baby without sticky blank slip. In the proposed practice, the baby and artefact are a kind of single functional unit that will alter the flow of care in significant ways.

\section{Black-boxing}

Neonatal intensive care is an equipment dense setting. The survival of the babies is dependent on their connection to complex equipment that monitors and adjusts the status of their physiological functioning (e.g., blood gases, hydration, nutrition and thermal regulation). Such equipment also 'black boxes' (Latour 1987) whole realms of medical and technical know-how. This is more than the automation of medical judgement and monitoring. Such equipment conceals and makes durable in material form medical know-how. They tie both the child and those using the readings and responding to alarms into a complex network of social, technical, conceptual and textual practices. The crucial position of such black boxes becomes apparent when their reliability comes into question as in Sequence 2:

\section{Sequence 2}

SR: $\quad$ Senior registrar, JR1/2/3 Junior Doctors

SR: there have been some problems with the billy machine are they all — are we confident with the billy machine at present?

JR1: it still clicks for us - you have to make sure you pull it out as far as it will go

JR2: which is the proper position? I think the proper position is

JR1: out isn't it? fully out isn't it [.] fully

JR3: It has to come from a true position yeh

JR1: Fully out yeh but there's as lightly in position that you could get if you're not cared -

JR2: And when it's not fully out it's just in that

SR: It reads about 40 lower or something [.] it reads higher I think or is it 40 higher? [.] to a significant degree so could we be very very careful about that

The 'billy machine' is a device routinely used for assessing blood chemistry of the baby and their liver function. Readings from the machine tie the baby and the unit into a whole set of contingent relations and outcomes in terms of the developing trajectory ofcare. Confidence in the reliability of the machine 
depends upon an assessment of the contingent medical and technical arrangements that are ongoing within the unit. We see how the technical quirks of this particular machine surface in the corroboration of its current reliability. For the black boxing to work the relationship between the affordances of the machine and the human agency of the operator must be aligned in terms of the "proper position" of the blood sample. Then the alliances of person, machine, baby and blood will provide for a durable set of contingent actions and interpretations of the current flow of care.

\section{Obligatory Points of Passage}

What it is to-be-in-the-know is a relevant concern of members of the unit. In the following example we see a discussion concerning the problems of predicting future workload. This is what is addressed below in Sequence 3, where the expanding possible case load is cut through identifying both calculation and discretion for admissions with a particular place - the labour ward. In other words, what will count as relevant workload is defined in terms of an obligatory point of passage - the labour ward. Such obligatory points of passage provide another resource for stabilising the contingencies in the flow of organisational practice.

\section{Sequence 3}

S: sister; SN: senior nurse; C: consultant

S: $\quad$ yeh sometimes / and I think it should say reserved cots and it should be indicating that they mean reserved cots in labour ward [yeh] because that's only the ones that we should be worried about is the ones that are round the corner (?: $\mathrm{mm}$ that's right) who are expected to deliver but I think when you put reserved cots I think that the interpretation could be different

$\mathrm{SN}$ : $\quad$ But $\mathrm{p}$ - people are always expanding that - if the - that they're always wanting one in brackets hydrop section tomorrow morning or that sort of thing

C: $\quad$ That's the problem I mean a hydropsbaby is at great risk it's gonna need intensive care and he is gonna have asection but he could actually be on the post natal ward until they take them down to the section

S: $\quad$ But that we would probably have that $\}$ in the diary and we would know about it (yes) what worries me is sometimes and quite often now and it's - it's quite a new thing at report you're actually hearing about what's lying upstairs $=$

C: $\quad$ yeh that's irrelevant it's nothing to do with -

S: $\quad$ I don't think we should bother about it $=[$

C: $\quad$ yeh we must dismiss that figure

S: $\quad$ you know but now you're told there's 29 weekers, 27 weekers 26 weekers but you don't want to know until they're down the labour ward but I do want to know about the hydropic one and er (yeh mm) you know $\{\ldots .$.

Accountability is critical here in terms of the capacity of the unit to cope with the demands of unpredictable work loads. What is at issue is the range and extent to which they should tailor their 
admissions in relation to potential problems. This turns around the question of what criteria should be used for determining the density of workload and the capacity to admit within there sources of the unit. One strategy is the reservation of space for upcoming deliveries of babies who may be in need of intensive care ("I think it should say reserved cots and it should be indicating that they mean reserved cots in labour ward"). However unless the delivery is earmarked as a caesarean section the actual timing of delivery for a baby who is likely to be born preterm is uncertain. Indeed the prolonging of the pregnancy usually increases the baby's viability and quality of developmental outcome. Reservation procedures are therefore problematic in a service that is set up to respond to emergencies. It is possible to end up in the situation where admissions are refused because the unit is theoretically at capacity when in fact a significant number of spaces are not currently occupied. The expectant mothers with preterm complications have not yet gone into labour, yet spaces are being reserved for their babies. The issue is how to cut the expanding range of possible births for whom the unit may well have to cater for.

The use of the "reserved cot" device has expanded. This means management by the unit over their space and the leeway for decisions concerning admissions has spun out of control ("when you put reserved cots I think that the interpretation could be different"; "people are always expanding that - if the - that they're always wanting one in brackets high drop section tomorrow morning or that sort of thing"). The range and relevance of just what reservation of space entails is called into question. There are clear circumstances where reservation makes sense ("That's the problem I mean a hydrops baby is at great risk it's gonna need intensive care and he is gonna have a section"). However what unfolds is the relationship between the place of the potential case - i.e., where the mother is currently resting, the post natalward or the labour ward - and reservation of space. The post natal ward is the place where mothers would be admitted to hospital for observation in advance of an impending section or delivery in a problematic pregnancy ("hydrops"). The labour ward is the place where birth occurs ("That's the problem I mean a hydrops baby is at great risk it's gonna need intensive care and he is gonna have a section but he could actually be on the post natal ward until they take them down to the section"). Such babies are also recorded as potential cases by other means ("But that we would probably have \{that\} in the diary and we would know about it [yes]"). The problem is that the use of reservation has extended to other cases who have been admitted to the post natal ward ("what worries me is sometimes and quite often now and it's - it's quite anew thing at report you're actually hearing about what's lying upstairs"). The unit is starting to have their workload determined by mothers who are on the post natal ward with pregnancies at different gestational stages ("you know but now you're told there's 29 weekers, 27 weekers, 26 weekers").

The solution to this expanding range of potential cases and accountability is to realign potential workload with those mothers who are actually on the labour ward except for exceptional cases that have specified sections arranged. Those cases lying upstairs are dismissed ("you don't want to know until they're down the labour ward but I do want to know about the hydropic one"). It is the significance of being on the labour ward that redefines the way in which "reserved cots" is interpreted in terms of space allocation. The labour ward in effect acts as a centre of calculation. Tying reservations to labour ward numbers cuts the expanding network of possible cases for whom the unit may well have to take account. The reserved cots / labour ward presence has an effect on the actions of the neonatal practice. Decisions concerning the capacity of the unit at any particular point in time are linked to a discretionary calculus configured in terms of an obligatory point of passage - the labour ward. 


\section{Recapitulation}

These initial examples demonstrate how the analytic resources of ANT go beyond a social network analysis of organisation ordering, towards a form of material analysis that traces how human and nonhuman entities are held together in producing stability as an emergent effect. This stability is a kind of solution to the problems posed by shifting and indeterminate relationships between people and things. This is the first sense of in which we find useful to speak about virtuality.

But ANT is itself problematic. Numerous critics have complained that ANT makes networks appear to be akin to powerful managerial control systems (Star 1991; Lee \& Brown1994). This potential for domination and surveillance certainly seems at odds with the kind of the neonatal care setting we are describing here, which often appears to be a fragile and unmanageable kind of network. ANT has also made much of how punctualisation / black boxing ensures that certain kinds of functionality become permanently embedded in particular technological artefacts (see Latour 1987; 1991). A laboratory test, for example, will always configure the materials to be tested in the same way and will always produce a certain standardised kind of results, irrespective of where the test is performed. But again, this is to accord to much to blackboxing. As Mol \& Law (1994) show in the case of tests for anaemia, the same artefact may be work in very different ways when moved across settings. As the example of the billy machine showed, participants do an awful lot of interpretative work around standardised results. What these results are taken to mean, what they are supposed to show, varies tremendously when contingencies such as the progress of the neonate or the experience of the doctor concerned are mobilised. Thus our second sense of virtuality: the potential of a thing always exceeds its current actualisation as such and such an entity.

This might suggest that networks have at their disposal infinite resources. That things can be rendered any way you like, so long as the right practices and techniques are in place. This, of course, is nonsense. As Lee \& Stenner (1999) put it "someone always pays". There are limits to what networks can do. The interesting question is not how networks endlessly grow and proliferate, but rather the ways in which they limit and circumscribe themselves. Neonatal care obviously limits itself in all sorts of ways, in accord with current knowledge, ideas about best practice, formal systems of accountability and so on. But these factors do not explain how in the ongoing flow of care these limitations are actually applied. What we will now try to analyse is the practical means by which the neonatal care network "turns back on itself". To do this we will need to draw on just a little more theory.

\section{Stabilising and Cutting Expanding the Networks Expertise}

As with analysis of networks in terms of social relations that are contingent upon continuities of identity and membership for their durability, "heterogeneous networks also have their limits" (Strathern 1996). But the issue is how are those limits established in practice. Theoretically such networks are infinitely extensible. Latour addresses this issue in terms of alliances - "networks in action are longer the more powerful the 'allies' or technological mediation that can be drawn in" (Strathern 1996, 523). But as Strathern points out such lengthening presupposes summation; "that is enumeration coming to rest in an identifiable object [the sum]". The question Strathern raises, and one we take up in this paper, is how do networks come to rest in terms of being "cut at a point: stopped " from further extension". This is not because we wish to argue that at such points we would have some irreducible fix on what the objects, events and circumstances are. Rather, we are interested in the way cutting the network of interdependent relations accomplishes what it is to be and not to be in-the-know as a participant in 
such networking. Our interest is in the way people turn around on and use the notion of heterogeneous networks at work in establishing accountabilities in practice and vice versa. The flows of knowing in practice are analysable in terms of the way accountability for outcomes of practice migrate and are tied into the network of human and non human objects, events, techniques and circumstances of practice.

Looking at the sorts of extracts like the above, we may be tempted to conclude that people in the intensive care unit spend all their time in conversation, passing the time, doing work, exchanging gossip, fixing procedures and shifts. And we might then go on to conclude that it is the interactional structure of such conversation that holds them all together, than binds them as co-workers. But we are not suggesting that. Already, it seems to us that there is something to be explained in the way that team members work is more than a discursive matter. They display an orientation to something else, something that cannot be explained by looking at the discursive formulation of objects.

To get a handle on what that might be, we turn to Michel Serres. What holds speakers together, according to Serres (1995), is that the things they exchange belong to neither one of them. The stories, incidents, lapses and successes originate elsewhere. Serres describes the joint attention to the extra-conversational origins of the exchange as a 'third party'. The third party, the space beyond the immediate communicative context that is nevertheless shared by the speakers present to one another is what makes communication possible. It is common medium, but also adjudicator, to whom both speakers can implicitly appeal to guarantee their own words. A kind of witness or unseen party towards whose presence both speakers orient their attention and partly efface their own contribution to the conversation - "Let me tell you something I heard".

That idea moves us forward. It suggests that there is something outside of the interaction, to which the interaction is directed and in some sense from which the interaction proceeds. So we may then ask what happens when these third parties become embedded within the babies who are the objects of care. How do these peculiar kinds of objects impress themselves on our conduct? What kinds of collectivity are implied by their movement?

The notion of the third, or 'thirdness', pervades Serres' thought (for example, Serres 1982; 1997). Thirdness is the space between two entities. It is the place where relationships are constituted, the medium through which an identity with regard to another can be taken up. Not quite one nor the other, but the in-between which has to be negotiated. Serres assigns various names to thirdness: parasite, third person, noise. In so doing he shifts between object, subject and attribute. In each case what is at stake is arguing whether thirdness is best described as a thing or as a relation. The point is beyond settling, since thirdness is, for Serres, both what makes identity possible, and that which continually threatens to undo identity.

Here is Serres best known example of thirdness. The rugby match:

"A ball is not an ordinary object, for it is what it is only if a subject holds it. Over there, on the ground, it is nothing; it is stupid; it has no meaning, no function and no value. Ball isn't played alone. Let us consider the one who holds it. If he makes it move around him, he is awkward, a bad player. The ball isn't there for the body; the exact contrary is true: the body is the object of the ball; the subject moves around this sun. Skill with the ball is recognised in the player who follows the ball and serves it instead of making it follow him and using it. It is the subject of the body, subject of 
bodies, and like a subject of subjects. Playing is nothing else but making oneself the attribute of the ball as substance" (Serres 1982: 225-6).

The ball by itself is nothing. It garners no meaning. But the ball in flight, the ball passed from hand to hand 'weaves the collective'. It organises the bodies which move in relation to its anticipated path. It is like the earth at the centre of the Ptolemaic universe, with the bodies of the players in orbit around it. To be a member of this collective is to make oneself become something in relation to the ball in flight. Or to make oneself into an attribute of the passing ball. A catch, a sprint, a dive. Bodies become 'participal acts' occasioned by objects.

There are two potential ambiguities here. The players gain their identity in relation to one another in terms of the irrelationship to the ball. Good players and bad players become such through the manner in which they take up a position in relation to the field of play which the ball defines. Yet at the same time, the players in the rugby team are modes of activity that the ball can open up. One is before or after, passing away from or toward the ball. The body of the player is a material link between two phases of the ball's passage, much a preposition in a sentence. Neither subject nor object, but the means of passage. A mediator.

Second ambiguity: what is the ball itself? Not really an object, too important for that. A sovereign or quasi-object, then. An object which is defined by the kinds of passages it undergoes and the effects it produces in the subjects and objects which surround it. Perhaps a kind of subject? No, the ball is what makes the adoption of subjectivity possible, it is the means by which subjects are marked out as such. So the ball is equally a quasi-subject. A third person. Neither the You or I, but the space against which this fragile relation is cast and whose presupposition alone lends meaning to the division of first and second person.

\section{The Baby as a Quasi/Virtual Object}

What we take Serres to be saying is that social relations are structured by quasi-objects. These are in turn peculiar species of objects. They are powerful, certainly, but they gain this power through their ability to lodge themselves in everyday interaction. They are objects in as much as one can point to them, describe them, evaluate them and so on. But because they are so important for interaction, they become in effect a kind of subject. That is, something to be negotiated and taken into account in a given interaction.

We argue that in neonatal care, it is the baby who acts as a quasi-object. It is the neonate around which the whole network revolves. The identities of each member are defined - sometimes moment to moment - by the relationship they have with the neonate. Thus a paediatrician may find himself/herself cycling between the identities of doctor, technician and counsellor as the trajectory of care unfolds or terminates. The neonate, then, in a way can be said to recruit members and materials around itself, which become its attributes: I am the person who will insert the catheter, this is the device which provides sodium readings, these are the drugs and techniques which will help respiration at this point. The neonate is what everything refers to. It is also the medium, the grounds upon which all other relations are premised. The relationship between members in the unit is derived from their joint positioning with regard to the baby. 
Perhaps this makes the baby appear to be the most powerful element in the network? That is an interesting paradox, because, of course, the baby is the weakest element, and it is the neonate's very fragility that is at stake in neonatal care. Perhaps this also sounds like we are being ambiguous about whether the baby is an object or a subject? Is it a human subject, endowed with rights, or an object to be manipulated by medical care? If we are ambiguous on this point it is because that ambiguity is a routine feature of the setting. What the neonate is - subject or object - is subject to continual negotiation. In particular, this occurs through a phenomenon we call scaling. This involves a shift in how the neonate is rendered or made actual. At times, the neonate is approached a bundle of interdependent biological systems (e.g. functional status of its organs, blood chemistry, homeostatic systems of temperature, hydration and perfusion). On other occasions, the neonate is treated as a child in relation to parents and professionals involved in its care. Consider the next example. Here the network of practice ties interdependencies of the child's physiological status, the practice of the unit in terms of its use of monitoring equipment, the parents as agents in the care of the child, even the child as a 'trustworthy' member of the trajectory of practice.

\section{Sequence 4}

\section{SR: $\quad$ Senior Registrar}

SR: $\quad$ and I think coming down to here in (low dependency) and (.) gradually - is a good thing (.) but it's a difficult balance to make (.) and for instance with David (.) he had $48 \mathrm{hrs}$ of observations of - of oxygen saturations in air and then we stopped (.) and unfortunately it took his mum and dad to say could we check his saturations (.) and I mean - and when we checked it (.) you know it was 69 erm and - and yet you can see how there is a balance between - we've got the oximeters here (.) we know they're not going on an oximeterat home (.) and we're planning for them to go home (yes) and so there is a temptation to say well no we're not (measuring oxygen levels) shall we just trust him and we just go on his - but then the oximeteris just there and it's round the corner so I think it is - it's tricky

The baby is what connects and binds interdependent accountabilities in practice where future trajectories of care (from high to low dependency; from hospital to home) reconfigure the topology of network practice. Moving within the unit from a regime of care in high dependency to low dependency involves a shift in the routines and techniques of monitoring the status of the babies health and development. What it is to generate relevant and collectively accepted knowledge conditions alters to such an extent that we see the child as entering into the network of agents potentially responsible for continuing trajectories of improvement ("shall we just trust him and we just go on his -").

The baby is the third party, the space beyond the immediate communicative context. It is the common medium to which all parties can appeal. The baby is both object (the person who moves), subject (the recipient of care) and attribute (a blood gas reading). Furthermore its status always has the potential of descending into chaos. As with the rugby ball the baby is no ordinary object. It too is what it is in terms of those actions that are done to it. It is precisely because of the interdependencies of care that it has such a problematic status. The granting of a lower level of care is where the baby is literally put into a form of circulation, or movement where it passes from hand to hand (from one grouping of staff to another, form staff to parents, to itself - "shall we trust him"). This movement of the baby is what the delivery of care (professional and/or parent) is accountable to. It weaves the collective - the social ordering and potential disorder of neonatal intensive care. 
So as with the rugby game the participants in neonatal intensive care gain their identity in relation to one another in terms of their relation to the baby (competent/negligent professionals; fussy/vigilant parents). The baby positions the participants. Parents and professionals are the link between phases in the babies passage/trajectory of care. Equally the baby is defined by the kinds of passages it undergoes and the effects it produces on the subjects and objects around it. Should professionals intervene? Should the ready to hand oximeter be used? Who should initiate intervention - "its tricky" —, parents or professionals? It makes its own and others subjectivity possible.

It is in this sense that we call the baby a virtual object. The neonate is always several things at once. What the neonate is changes dramatically as it is scaled up or down by members in the course of care. The baby is the subject/object around which the entire unit turns. But it is also put into circulation - both literally as it passes through different phases of care, and in the form of sets of readings, forms, records and outcomes. We find it useful to describe this ambiguous identity and location as functional blankness. It is precisely because the neonate may be made actual in so many different ways that it is able to serve as the grounds for mobilising so many different people and materials. It is precisely because we do not know what this neonate is, what it may become as the contingencies of the setting change, that so much organisational effort is expended at weaving a complex network around it. But at crucial moments a clear identity - even a form of agency — is attributed to the child. Why should this be so?

\section{Potential Multiplicity and Cutting the Network by}

\section{Attributing Agency to Neonates for Outcome and Viability}

The baby is never singular. It is always potentially multiple and stabilised both literally and figuratively as different discrete things as part of ongoing trajectories of care. Making visible and using networks of accountability in practice brings with it alignments of knowing, perspective and outcome. When outcome is uncertain as it frequently is in intensive care, then the ownership or alignment of knowing with particular agents in practice is problematic. Being-in-the-know becomes part of the social ordering of accountability for the outcome of intensive care. The network expands in the search for rendering durable accountabilities of knowing-in-practice. The formulation of the baby's agency as a hybrid of discursive and non-discursive orderings will be discussed. The deployment of such agency demonstrates another way in which the topology of expanding networks of knowing are rendered sufficiently stable whilst obviating the problematic of accountability that comes with being-in-the-know. In discussing the attribution of agency to place and persons we are not treating 'agency' as some property that infuses the human and the non-human in equivalent ways, i.e., "as some substantive, unitary and pervasive force" (c.f. Lynch 1996, 249).

Such trajectories of working are also a continual folding in of technique, technology, expertise and relationship. The challenge in defining trajectories of participation is the ordering of one in terms of the other. Hold social relationships steady and disorderings of technique and technology can become the focus of analytical concern, i.e. agreement on how or when to proceed will implicate a range of technical and material orderings. Hold the world of technique and material steady and the relationships that are mediated through such material ordering can become the subject of scrutiny. Of course at times of uncertainty the possible network of relational and technical relevances expands. The issue is how to bring about closure in producing a form of durable knowing in the working 
network. One of the ways in which we see closure being accomplished is though the way agency is invoked and deployed. A particular form of agency embedded/enmeshed in the baby as a hybrid of intentionality and technical practice (equipmentality) is invoked (see Strathern 1996 for a more detailed discussion of cutting the expansion of networks, and Brown and Capdevila 1999 on functional blankness and agency). One of Strathern's main points is that nature is often mobilised to cut sociality and vice versa. In the following example such distinctions are constantly unravelling or meaningless. Agency is never something that is purely 'just there' (i.e. natural) nor is it something 'agreed upon' (i.e. legal or social). Agency is instead an effect arrived at by moves that implicate both the social and the nature, the technological and the human, expertise and emotion.

The final example was recorded at a routine meeting where the pathologist reported back on a recent post mortem. Agency in hybridity can be seen as a powerful means of cutting the expanding network of possible explanations concerning the possible reasons for the death of a child who was born extremely prematurely.

\section{Sequence 5}
P: Pathologist; SR: Senior Registrar; C: Consultant
P: $\quad$ so I think that that this child was probably previable
?: [indistinct side conversation in relation to case notes]

[3 seconds]

P: I don't think that its insterstitium was up to - err its lung insterstitium

C: did it have PIE insterstitium emphysema on the [...]

? [reading out chest X-ray report] and sounds of slide projector carousel being returned to the beginning

[33 seconds]

SR: what about e coli?

P: $\quad$ yes well there was no evidence of septicaemia but it was you had an infected catheter tip it was in the arm pit and it was in the blood so uh I think it was probably an early an early one

?: $\quad$ um

C: $\quad$ and I am sure you are right I am sure you are right it was probably previable then the course of survival at 24 weeks then the brain just could'nt stand the intensive care needed for the lungs could it?

P: well I think that's right that's absolutely right now the other interesting thing about it is $\underline{\text { s }}$ that this child was responding the child was trying physiologically because the thymus showed tremendous stress involutionary action and in those cases where you have them die um (.) and you don't have a blown brain very often you do not find any thymic reaction at all and the 
child just sort of gave up without without a fight but its where they are fighting and they're trying to survive that's when you get er the the blown brain

C: um

\section{[4.0 seconds]}

C: $\quad$ what about Jane and the parents - think they will come back from $<$ City $>$ for counselling

This part of the discussion comes after the pathologist has presented a range of histological and photographic evidence concerning the possible causes of death. The presentation hangs on the issue of whether this child was 'previable', i.e. given the regimes of care currently available within the NICU were the team operating beyond the limits of the gestational viability of the child. Were they operating beyond the limits of viability? Or was there any evidence that could indicate inappropriate deployment of known interventions, i.e. their use of technology, technique and medical understanding had been inadequately deployed on a baby who might have survived. Could modifications of practice have lead to a different outcome? Or was it that no amount of technical and medical artifice was going to lead to an outcome where the child was on a trajectory of survival? In the extract all the evidence has been presented by the pathologist. The presentation focused on lung and brain function ended with an open ended assertion by the pathologist ("so I think that that this child was probably previable").

The interesting thing is that the participants at the meeting neither confirmed nor reformulated this hedged assessment (see Prince, Frader and Bosk 1982) for a discussion of the use of hedges in the discursive treatment of uncertainty in paediatric intensive care and in other medical contexts (Atkinson 1995). This assessment engendered no direct acknowledgement by team members of their actions as having material effect on the outcome in either way. This is interesting because as Antaki $(1994,69-$ 91) discusses (in relation to the work of Pomerantz [1984] and Levinson [1983]) such assessment provides for an "explanation slot". Assessment formulations work sequentially to engender agreement. Non-agreement is interactionally accountable. We see this in the continuing expansion of the topology of possible candidates for inclusion in the explanatory network. They engage in further archaeology of the case notes and medical records - (indistinct side conversation in relation to case notes - 3 seconds ). The pathologist then scales up the notion of previability in providing further morphological details ("I don't think that its insterstitium was up to - err its lung insterstitium"). The locus of interpretation and assessment is located within constitutional features of the child's morphology, its physiological status but still in hedged terms - ("I don't think that, etc."). This still does not provide for closure. Instead it leads to further concerted effort by participants lasting over half a minute to confirm and expand the realm of corroborative and other candidate explanations ("did it have PIE insterstitium emphysema"; "what about e coli?"). The pathologist elaborates this expanding field of possible explanations with indirect confirmation of nascent potential for septicaemia ("yes well there was no evidence of septicaemia but it was you had an infected catheter tip it was in the arm pit and it was in the blood so uh I think it was probably an early an early one"). Each move to expand the possible explanation also expands the network topology, and thus speeds up circulating accountabilities which therefore become more difficult to settle.

The team members have not displayed acceptance of the pathologists' assessments concerning previability. Neither have they not closed down further searches. Previability is a sensitive area of concern. It raises all sorts of issues concerning the moral and ethical status of their interventions in relation to the level of aggressiveness in the treatment of 'previable' babies. The 'ownership' of the conclusion to be drawn is made relevant in the way the speakers perspectivise the conclusion on 
possible previability. They foot (Goffman 1981) the conclusion as the property of the other ("and I am sure you are right I am sure you are right it was probably previable then the course of survival at 24 weeks then the brain just could'nt stand the intensive care needed for the lungs could it?"). The trajectory of survival was one that meant that a particular element of the system was not going to withstand intensive care.

But note how the durability of the conclusion is aligned with the other speaker ("I am sure you are right I am sure you are right"). The tag question ("could it?") provides for a further explanation slot (Antaki 1994) for the pathologist. So not only is the utterance aligned with the pathologist in terms of his 'rightness', the formulation of the acceptance invites further contributions from the potential recipient. The pathologist's hedged assessment is accepted but in so doing the pathologist is rendered accountable for the conclusion. What is interesting is the way this further exploration of probable cause is terminated. The pathologist's explanatory agreement is accomplished in an interesting manner. Again the response is aligned as the property of the other ("well I think that's right that's absolutely right"). It is the other person's reformulation of the putative circumstances of previability that are accepted 'absolutely' contrasted with the hedged conditionality of "I think that's right". This contrast between the 'conditional' and the 'absolute' leaves in play the continuing misalignments of the utterance with the utterer. This reciprocal realignment of the conclusion with the other's perspective leaves the network of possibilities open. Indeed at this juncture the network of possible candidate reasons for death is expanded still further. The interesting question here is why this aligning of accounts isn't enough — why can't they settle the matter here through some deft alignment work?

We argue that it is in the way that this expansion is formulated that brings off the cutting of the expanding network of potentially relevant explanations in a way that exempts either of the parties from being directly aligned with the conclusion. The network of possible relations is cut by factoring in the baby as an agent in its own survival ("now the other interesting thing about it is is that this child was responding the child was trying physiologically because [...]"). The interesting thing is the way the child's agency is worked up. The child is a physiological hybrid - a being who is known in terms of some technique of histological examination ('thymic reaction') that shows its will-to-live. Such agency is not grounded in some anthropomorphic reading of the baby's putative intentions as a sentient being but in terms of interdependencies of being in relation to other realms of knowing - the pathologists' practice and presentation of histological evidence. Why do they expand and condense the network around the child's agency? Could it be because of a strange inversion where 'medical agency' is very weak - doctors can't seem to arrive at a conclusion, they appear to parents as driven by the accountabilities in play and by professional loyalty -, where the agency of the child is paradoxically very strong - it appears 'outside' of sociality and driven by a pure will to live? Thus the stronger form of agency, the one which will settle circulating accountabilities and cut the network, is recognised in the child. The network then orients around this.

What does this working up of agency in these terms accomplish both in terms of this particular child ("this child was responding the child was trying physiologically") and in terms of cases in general ("where you have them die um (.) and you don't have a blown brain very often" and "where they are fighting and they're trying to survive that's when you get er the the blown brain"). The alignment of previability with outcome (accountability for outcome) is shifted to the baby. It is a previable child who fights for survival and in so doing incurs the danger of blowing its own cerebral system. The ownership of the consequences of previability have now been aligned with the baby's "endeavour to persist". The network of medical knowledge, technique, nursing practice, pathology and physiological reaction are 
ordered in a way that cuts the expanding network. This is not just another difficult physiological homeostatic breakdown of regulative functioning as demonstrated through the histological practices and presentation. The medicine, the physiology, the interventions, etc., are all now focused and folded in through the agency of the baby in this particular case. In addition a class of evidence is also characterised in these previable cases in general where fighting for survival results in regulative disaster.

The debate stops and moves on to issues concerning relationships with parents. Closure is accomplished, the expanding network of possibilities is cut via the migration of agency (being-intechnique) that provides accountability for outcome in terms of previability. The durabilities of conclusions concerning the uncertainties of practice and outcome are not now aligned with medical and nursing expertise, i.e. possible inadequate judgements over levels of care and intervention, nor are they centred on the pathological practices of histological interpretation. The baby as a hybrid of agency in the endeavour to persist and the complex of physiological reasoning and histological interpretations provides for a stable ordering of circulating uncertainties. The Gordian knots of the networking in socio-technical relationships are cut (see also Strathern 1996 for discussions of ownership and hybridity in cutting networks).

\section{Conclusion}

In this paper we have offered a description of a neonatal intensive care unit as a hybrid network of people, material, technical artefacts and techniques. We have tried to show how this network is characterised by radical ambiguity. They form a problematic field that is 'solved' in different ways by assigning identities and relationship. We have offered the terms virtual and actual for as a way of orienting to this process. As we see it, the benefit of these terms is that they sensitise us to the production of order as a provisional achievement, as a solution to a problem. We then assume that order-making is not solely an interaction achievement, as that phrase is usually understood. The interactional order of social life is made up of things as well as people, and the myriad ways in which they connect and jointly mediate one another's relationships.

The approach which we have taken is broadly informed by actor-network theory. But with some qualifications. What we have described is a network that is far too uncertain and ambiguous in its functioning to be called powerful. Furthermore, the baby, who we have described as holding the network together, is potentially the weakest element. Unlike traditional actor-network stories, which revolve around powerful figures like Pasteur or impressive achievements like the maintenance of great sea trading routes, our account turns around the fragile and powerless neonate. It is the weakest, the least well defined entity which turns out to be thing which holds the network together.

ANT is notorious for claiming no a priori difference between people and things (Latour 1992). For good reasons - it wants to understand the grounds upon which this division is made. But it cannot subscribe to that here. The baby is not an actant like any other. Not because it is clearly a subject, since it can also be rendered as an object. Nor because it is in some way natural, since it only exists by virtue of modern technology. Nor, finally, because it is endowed with some quintessential human agentic powers. No, the baby is different because it is the blankest thing in the network, the virtual object which appears to offer the greatest potential to be rendered up in multiple different ways. 
This blankness seems integral to the way the baby holds the network together. That is why we call it functional. And is not functional blankness precisely what we mean by agency? What is it that allows for the attribution of agency? It is the sense that someone or something is not following some preestablished programme of action, is not simply expressing some pre-existing structure. Agency is a kind of ambiguity, a break with what we expect. The exercise of agency is a break, a rendering of oneself as otherwise that what was previously understood to be the case. A radical ambiguity. Or, to come full circle, a form of virtuality.

\section{References}

Antaki, C. (1994). Explaining and Arguing: The social organisation of accounts. London: Sage.

Atkinson, P. (1995). Medical talk and medical work. London Sage.

Bayer, B. \& Shotter, J. (eds.) (1997). Bodies, technologies and subjectivity. London: Sage.

Berg, M. (1997). Rationalising medical work: Decision support techniques and medical practices. Cambridge MA: MITPress.

Billig, M. (1987). Arguing and Thinking. Cambridge: Cambridge UniversityPress

Boden, D. and Zimmerman, D.H. (1991). Talk and social structure: Studies in ethnomethodology and conversation analysis. Cambridge: Polity Press.

Brown, S.D. and Capdevila, R. (1999). "Perpetuum mobile: substance, force and the sociology of translation". In J. Law and J. Hassard (eds.). Actor network theory and after. Oxford: Blackwell.

Brown, S.D. \& Lightfoot, G. (2002). "Presence, absence and accountability. Email and the mediation of organisational life". In S. Woolgar (ed.). Virtual Society? get real! Buckingham: Open UniversityPress.

Brown, S.D., Middleton, D.J. and Lightfoot, G. (2001). "Performing the past in electronic archives: Interdependencies in the discursive and non-discursive ordering of institutional remembering". Culture and Psychology. Vol. 7(2): 123-144.

Burt, R.S. (1982). Towards a structural theory of action: Network models of social structure, perceptions, and action. New York: Academic Press.

Callon, M. and Law, J. (1995). "Agency and the hybrid collectif". The South Atlantic Quarterly 94(2): 481-507.

Callon, M. (1986). "Some elements of a sociology of translation". In J. Law (ed.). Power, action and belief. London: Routledge and KeganPaul.

Deleuze, G. (1997). Negotiations. London: Athlone.

Domènech, M., \& Tirado, F. (2001). "The virtual and the social". Presented at the Social Psychology of the Virtual, British Psychological Society Social Psychology Section Annual Conference, University of Surrey, 18-20 July 2001. 
Edwards, D. \& Potter, J. (1992). Discursive psychology. London: Sage Publications.

Goffman, E. (1981). Forms of talk. Oxford: Basil Blackwell.

Gordo-López, A.J. \& Parker, I. (eds.) (1999). Cyberpsychology. London: Macmillan.

Hendriks, R. (1997). "On words and clocks: Temporal ordering in a ward for autistic youths". In K. Hetherington \& R. Munro (eds.). Ideas of difference. Oxford: Blackwell.

Latour, B. (1987). Science in action. Cambridge, Mass.: Harvard University Press.

Latour, B. (1988). The pasteurization of France \& Irreductions. Cambridge, Mass: Harvard University Press.

Latour, B. (1991). "Technology is society made durable". In J. Law (ed.). "A sociology of monsters. Essays on power, technology and domination". Sociological Review Monograph. Vol. 38. London: Routledge.

Latour, B. (1992). "Where are the missing masses?" In W.E. Bijker \& J. Law (eds.). Shaping technology/building society, Cambridge, Mass.: The MIT Press.

Law, J. (1992a). "Notes on theory of actor-networks". Systems Practice 5(4): 379-393.

Law, J. (ed.) (1992b). "A sociology of monsters. Essays on power, technology and domination". SociologicalReview Monograph. Vol. 38. London: Routledge.

Lee, N. \& Brown, S.D. (1994). "Otherness and the actor network". American Behavioural Scientist, 37(6), 772-790.

Lee, N. \& Stenner, P. (1999). "Who pays? Can we pay them back?" In Law, J. \& Hassard, J. (eds.). Actor-network theory and after. Oxford:Blackwell.

Levy, P. (1998). Becoming virtual. NewYork: Plenum Press.

Levinson, S. (1983). Pragmatics. Cambridge: Cambridge University Press.

Rodríguez, I., López, D. and Vitores, A. (2001). "A world without walls". Presented at the Social Psychology of the Virtual, British Psychological Society Social Psychology Section Annual Conference, University of Surrey, 18-20 July 2001.

Lynch, M. (1996). "DeKanting Agency: Comments on Bruno Latour's Interobjectivity. Mind Culture and Activity, 3(4), 246-258.

Michael, M. (2000). Technology, nature and culture. London: Routledge.

Middleton, D. (1996a). "Talking work: Argument, common knowledge and improvisation in multidisciplinary teams". In Y. Engestršm \& D. Middleton (eds.). Cognition and communication at work. Cambridge: Cambridge University Press.

Middleton, D. (1996b). "A discursive analysis of psychosocial issues: Talk in a 'parent group' for families who have children with chronic renal failure." Psychology and Health, 11: 243-260.

Middleton, D. (1997a). "The social organisation of conversational remembering: Experience as individual and collective concerns". Mind, Culture and Activity, 4 (2): 71-85. 
Middleton, D. (1997b). "Conversational remembering and uncertainty: interdependencies of experience as individual and collective concerns in team work", Journal of language and Social Psychology ${ }_{2}$ 16(4): 389-410.

Middleton, D. (1998). "Reasonable Circumstances and Outcomes: Psychosocial support and socially remembered dilemmas in parents talk about their care of children with chronic renal failure". In Resnick et al. Discourse, Tools and Reasoning. Springer-Verlag.

Middleton, D. (2002). "Succession and change in the socio-cultural use of memory: Building in the past in communicative action". Culture and Psychology, 8(1): 79-95.

Middleton, D., Brown, S.D. and Curnock, D. (2000). "Topologies of durability and transformation in networks at work: Exploring the organisation of accountability and agency in neonatal intensive care". Conference proceedings of the 3rd Conference for Socio-Cultural Research "New Conditions of Knowledge Production: Globalization and Social Practices". Unicamp, Campinas, Sao Paulo, Brazil, 16-20 July 2000.

Middleton, D. and Curnock, D. (in press). "Talking matters at work: Arne Raeithal's scholarship and the semiotic regulation of co-operative work". Mind Culture and Activity.

Mol, A. \& Law, J. (1994). "Regions, networks and fluid: Anaemia and social topology". Social Studies of Science, 24(4): 641-672.

Pomerantz, A. (1984). "Agreeing and disagreeing with assessments: some features of preferred/dispreferred turnshapes". In J.M. Atkinson and J. Heritage (eds.). Structures of social action: Studies in conversational analysis. Cambridge: Cambridge University Press.

Potter, J. and Wetherell, M. (1987). Discourse and Social Psychology. London: Sage Publications.

Prince, E.F., Frader, J. and Bosk, C. (1982). "On hedging in physician-physician discourse". In R.J. DiPietro (ed.). Linguistics and the professions, Norwood, N.J.: Ablex.

Raeithel, A. (1994). "Symbolic production of social coherence. The evolution of dramatic, discursive and objectified meaning systems". Mind, Culture and Activity, 1: 1-2, 69-88.

Raeithel, A. (1996). "On the ethnography of co-operative work". In YrjoEngestršm and David Middleton (eds.). Cognition and communication at work. Cambridge: Cambridge University Press. P. 319- 339.

Serres, M. (1982). The parasite. Baltimore: Johns Hopkins.

Serres, M. (1995). Angels: A modern myth. Paris: Flammarion.

Serres, M. (1997). The troubadour of knowledge. Ann Arbor: University of Michigan Press.

Star, L. (1991). "Power, technology and the phenomenology of conventions" In J. Law (ed.). A sociology of monsters. Essays on power, technology and domination. Sociological Review Monograph (vol. 38). London: Routledge.

Strathern, M. (1996). "Cutting the network". J. Roy. anthrop. Inst, (2): 517-535.

Wasserman, S. and Galaskiwicz, J. (eds.) (1994). Advances in social network analysis: Research in the social and behavioral sciences. Thousand Oaks, CA: Sage Publications. 
Woodrow, J. (2001). "Digital photography as virtual society". Presented at the Social Psychology of the Virtual, British Psychological Society Social Psychology Section Annual Conference, University of Surrey, 18-20 July 2001.

\section{Acknowledgements}

Thanks to David Curnock, Trudi Cameron and members of the Intensive Care Service for their interest and support.

\section{Referencia}

Middleton,D. y Brown,S. (2002). The Baby as a Virtual Object: Agency and Stability in a Neonatal Care Unit. Athenea Digital, 1. Disponible en http://antalya.uab.es/athenea/num1/Mmiddleton.pdf 